\title{
Effect of correcting for gestational age at birth on population prevalence of early childhood undernutrition
}

\author{
Nandita Perumal ${ }^{1,2^{*}}$ (D) Daniel E. Roth ${ }^{2,3,4 \dagger}$, Johnna Perdrizet ${ }^{1}$, Aluísio J. D. Barros ${ }^{5}$, Iná S. Santos ${ }^{5}$, \\ Alicia Matijasevich ${ }^{5,6}$ and Diego G. Bassani ${ }^{1,2,3+}$
}

\begin{abstract}
Background: Postmenstrual and/or gestational age-corrected age (CA) is required to apply child growth standards to children born preterm ( $<37$ weeks gestational age). Yet, CA is rarely used in epidemiologic studies in low- and middle-income countries (LMICs), which may bias population estimates of childhood undernutrition. To evaluate the effect of accounting for GA in the application of growth standards, we used GA-specific standards at birth (INTERGROWTH-21st newborn size standards) in conjunction with CA for preterm-born children in the application of World Health Organization Child Growth Standards postnatally (referred to as 'CA'strategy) versus postnatal age for all children, to estimate mean length-for-age (LAZ) and weight-for-age (WAZ) z scores at 0, 3, 12, 24, and 48-months of age in the 2004 Pelotas (Brazil) Birth Cohort.
\end{abstract}

Results: At birth $(n=4066)$, mean LAZ was higher and the prevalence of stunting $(L A Z<-2)$ was lower using CA versus postnatal age (mean \pm SD): $-0.36 \pm 1.19$ versus $-0.67 \pm 1.32$; and 8.3 versus $11.6 \%$, respectively. Odds ratio (OR) and population attributable risk (PAR) of stunting due to preterm birth were attenuated and changed inferences using CA versus postnatal age at birth [OR, 95\% confidence interval (Cl): 1.32 (95\% Cl 0.95, 1.82) vs 14.7 (95\% Cl 11.7, 18.4); PAR 3.1 vs 42.9\%]; differences in inferences persisted at 3-months. At 12, 24, and 48-months, preterm birth was associated with stunting, but ORs/PARs remained attenuated using CA compared to postnatal age. Findings were similar for weight-for-age $z$ scores.

Conclusions: Population-based epidemiologic studies in LMICs in which GA is unused or unavailable may overestimate the prevalence of early childhood undernutrition and inflate the fraction of undernutrition attributable to preterm birth.

Keywords: World Health Organization Growth Standards (WHO-GS), Gestational age, Growth, Preterm birth, Pediatrics, INTERGROWTH newborn size standard

\section{Background}

Early childhood growth is an important indicator of a child's future health and developmental potential $[1,2]$. Childhood undernutrition-defined by weight and/or length/height more than 2 standard deviations below the standard population median for age and sex-has been associated with an increased risk of mortality $[1,3]$, poor

\footnotetext{
*Correspondence: nandita.perumal@sickkids.ca

${ }^{\dagger}$ Daniel E. Roth and Diego G. Bassani are joint senior authors

${ }^{2}$ Centre for Global Child Health, Child Health Evaluative Sciences, Hospital

for Sick Children, 686 Bay Street, Toronto, ON M5G 0A4, Canada

Full list of author information is available at the end of the article
}

cognitive development [4], lower school achievement [5], lower economic productivity [6], and a greater risk of adverse cardiometabolic outcomes [7-9] later in life. Undernutrition represents a major public health burden in low- and middle-income countries [10, 11]. Preterm birth, defined as births < 37 weeks gestational age (GA), has been consistently identified as a major risk factor for undernutrition in early life [12-15]. However, population-based estimates of undernutrition attributable to preterm-birth may be biased if they do not account for the GA of preterm-born children in the application of growth standards. 
The World Health Organization Child Growth Standards (WHO-GS) are the most widely accepted international normative standards for evaluating postnatal growth among children less than 5 years of age $[16,17]$. These standards are not directly applicable to children born preterm using postnatal age because they are based on a reference population of term-born children (births between 37 and 42 weeks GA) [18]. In clinical practice, guidelines commonly recommend correcting the postnatal age of children born preterm for the number of weeks that birth occurs prior to term gestation (40 weeks) to generate a 'GA-corrected age' (CA), which is then used to apply the WHO-GS up to 24 or 36 months of postnatal age $[19,20]$. This strategy along with the recent publication of the GA-specific norms, INTERGROWTH-21st newborn size standards (IG-NS) [21] and INTERGROWTH-21st very preterm size at birth references (IG-VPBR) [22], provide new methods to account for GA in the standardization of anthropometric measures at birth and postnatally among children born across range of GA in population-based studies.

The importance of accounting for GA in the timescale for evaluating neonatal outcomes is well-recognized in perinatal epidemiology [23], and the implications of disregarding GA at birth in the application of growth standards/reference have been previously established in clinical settings [24, 25]. Yet, in population-based epidemiologic studies of undernutrition in LMICS, in which children born across a wide range of GA are typically included, CA is rarely used in the application of growth standards to preterm-born children [26]. Ignoring GA at birth penalizes children with shortened gestational duration and conflates those who are small but wellnourished given their GA at birth with children who have biologically meaningful deficits in nutritional status.

To quantify the implications of not accounting for GA at birth in the application of child growth standards for population-based estimates of undernutrition in LMICs, we compared the use of a ' $\mathrm{CA}$ ' strategy, which applied GA-specific standards at birth in conjunction with WHO-GS using CA for preterm-born children postnatally, versus postnatal age in the application of WHOGS for all infants (as is done conventionally), to estimate mean nutritional indices and indicators (prevalence of stunting and underweight) in a population-based cohort of term- and preterm-born children less than 5 years of age in Brazil. Additionally, we aimed to estimate the proportion of stunting and underweight attributable to preterm birth in the first 5 years of life using CA versus postnatal age strategy.

\section{Methods}

Study sample

Anthropometric data from the 2004 Pelotas Birth Cohort study were used. The cohort study methods have been described in detail elsewhere [27, 28]. Briefly, all births occurring in the five maternity hospitals in the urban areas of Pelotas, Brazil, from January 1st to December 31st 2004 were eligible for inclusion in the birth cohort study. Perinatal outcomes were ascertained from hospital records at the time of delivery. After birth, children were scheduled for follow-up at 3, 12, 24 and 48 months of age. Data on child anthropometry was collected at each follow-up. Follow-up rates at 3, 12, 24 and 48-month visits were high: $95.7,93.6,93.4$, and $91.8 \%$, respectively [27, 28]. The cohort study was approved by the Research Ethics Committee of the Medical School of the Universidade Federal de Pelotas for all follow-ups and, in addition, the World Health Organization Ethics Committee (Geneva) for data collected at birth. Ethical approval for this analysis was obtained from the Hospital for Sick Children, Toronto, and the University of Toronto, Canada.

\section{Measurements Gestational age}

GA at birth was measured by three different methods: (1) the Dubowitz score based on the physical and neurological characteristics of the newborn; (2) date of the last menstrual period (LMP), as reported on a mother's prenatal card or self-reported during perinatal interview; and (3) ultrasonography evaluation performed before 20 weeks of pregnancy, as recorded on the mother's prenatal card [27]. Although GA assessment using ultrasound in the first trimester is the most valid measure [29], we observed substantial selection bias due to missing data in ultrasound-based GA assessment. In addition, prenatal care facilities in Pelotas did not use standardized ultrasonography methods for GA assessment. Therefore, we created a GA variable using LMP when it was available, and Dubowtiz scores when LMP was missing or when GA assessment according to LMP was $\leq 22$ or $\geq 45$ weeks.

To check for plausibility of GA estimate, we used the best available normative reference/standards for GAspecific size at birth to flag implausible GA values. Using a conservative approach, observations were flagged $(n=215)$ if birthweight-for-GA was outside the range of (1) \pm 2 standard deviations (SD) according to the Fenton growth curves [30] for births between $22^{0 / 7}$ and $32^{6 / 7}$ weeks and IG-NS [21] for births between $33^{0 / 7}$ and $36^{6 / 7}$, and (2) outside $\pm 3 \mathrm{SD}$ according to the WHO-GS 
at age ' 0 ' for children born $\geq 37$ weeks. If a flagged GA was based on LMP, a plausible Dubowitz score was used $(n=174)$. To minimize the loss of data, flagged observations for which GA based on both LMP and Dubowitz was outside the \pm 2 SD range $(n=11)$, were flagged again to assess if these values were within \pm 3 SD of the birthweight-for-GA using either GA based on Dubowitz score $(n=9)$ or LMP $(n=1)$ since values within this range were less likely to be due data entry errors. Flagged observations were set to missing when, (1) GA estimates were outside \pm 2 SD of the birthweight-for-GA range and had only one recorded GA assessment method (i.e. LMP or Dubowitz only, therefore could not be corroborated with another method of GA assessment) $(n=30)$, and (2) they were outside \pm 3 SD birthweight-for-GA based on both LMP and Dubowitz $(n=1)$.

\section{Age scales}

Postnatal age at each follow-up visit was calculated by subtracting the date of the child's birth from the calendar day of the visit. For children born preterm, CA in the postnatal period was calculated as the difference between the GA at birth and a full-term gestational duration of 280 days (40 weeks), and then subtracting this difference from the postnatal age: $\mathrm{CA}=[$ Postnatal age - (280 days - GA at birth)] [20]. For example, at 8 weeks postnatal age, a child born at 35 weeks GA would have a CA of 3 weeks and therefore would be compared to term-born children who are 3- weeks postnatal age. At birth, postmenstrual age/GA was used directly; therefore, estimates derived from using postmenstrual age at birth and $\mathrm{CA}$ for preterm-born children during postnatal visits are collectively referred to hereafter as ' $\mathrm{CA}$ '.

\section{Anthropometric measures}

Methods used for anthropometric assessment of children in the Pelotas 2004 cohort were previously described [27]. Briefly, child length and weight were measured using a standardized protocol by trained interviewers who underwent standardization sessions every 3 months. Length at birth was measured with $1 \mathrm{~mm}$ precision using a foldable wooden length board specifically designed for the study. Birthweight was obtained from nursing records, which, in all hospitals, was measured using electronic pediatric scales with $10 \mathrm{~g}$ precision [27]. At 3, 12, and 24-month visits, the mother held the child for weight measurement. Maternal weight (no child) and the weight of clothes for the mother and the child were recorded separately. At the 48-month visit, the child was weighed (with minimal clothing). Weight measurements at postnatal ages were obtained using an electronic scale with $100 \mathrm{~g}$ precision. Maternal weight, where applicable, and weight of any remaining clothes, measured separately, were subtracted to calculate the child's final weight.

\section{Application of growth standards}

At birth, length-for-age (LAZ) and weight-for-age (WAZ) $z$ scores were derived using 0 day when applying the WHO-GS and CA when applying the IG-NS (Fig. 1). Since the IG-NS are based on a cohort of children born

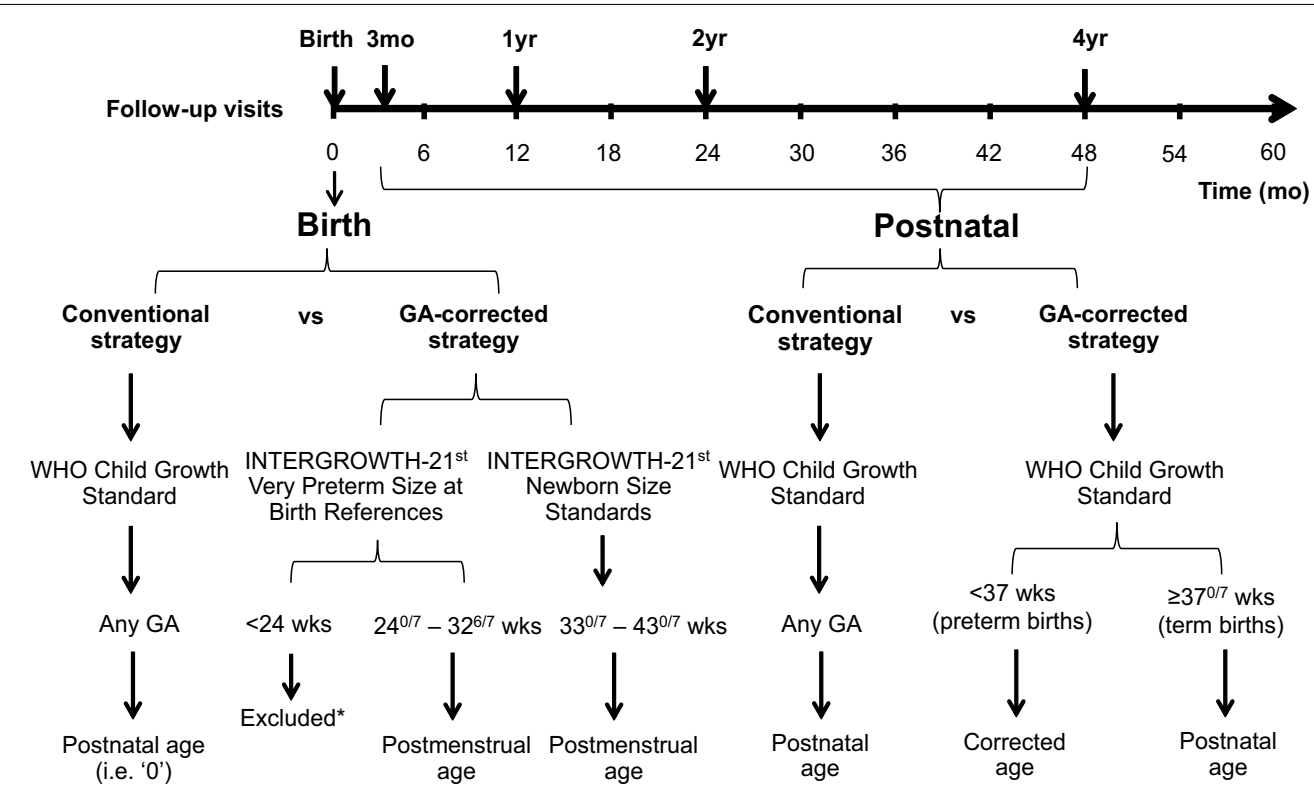

Fig. 1 Hierarchical strategy for the application of neonatal size and postnatal growth standards using postnatal or postmenstrual timescales at various follow-up visits. * INTERGROWTH very preterm size at birth references are not applicable to infants born at < 24 week gestational age 
between $33^{0 / 7}$ and $42^{6 / 7}$ weeks GA [21], we used the IGVPBR for children born between $24^{0 / 7}$ and $<33$ weeks GA [22], and truncated births $(n=127)$ at $>43^{0 / 7}$ weeks GA to 300 days ( $43^{0 / 7}$ weeks) to permit application of the IG-NS and minimize the loss of data at birth. For one female infant born at 231 days GA, we used 232 days GA to derive $z$ scores at birth because IG-NS do not estimate $z$ scores for female infants born specifically at 231 days GA.

In the postnatal period beyond day 0, LAZ and WAZ were derived using the WHO-GS based on either the (1) postnatal age for all children, or (2) postnatal age for term-born children and CA for preterm-born children. In primary analyses, we did not use $\mathrm{CA}$ at postnatal ages for children born at early term GA (i.e., 37 or 38 weeks) using CA versus postnatal age in the application of size/ growth standards at birth, 3, 12, 24 and 48-month visits. Indicators of undernutrition were the proportion of children classified as stunted (LAZ $<-2 \mathrm{SD}$ ), underweight (WAZ $<-2 \mathrm{SD}$ ), and wasted (weight-for-length $z$ score $(\mathrm{WLZ})<-2 \mathrm{SD}$ ) at each visit. Paired Student's $t$ test and McNemar's test for paired proportions were used to evaluate differences in means and proportions, respectively. The odds of undernutrition among preterm-born children (exposed) relative to term-born children (unexposed) at each follow-up visit were estimated using unadjusted logistic regression. We also determined the population attributable risk percent (\% PAR) of undernutrition due to preterm birth using the following formula [33]:

$$
\left(\frac{\text { Risk }_{\text {Preterm }}-\text { Risk }_{\text {Term }}}{\text { Risk }_{\text {Preterm }}}\right) \times\left(\frac{\text { No. of preterm born children stunted } / \text { underweight }}{\text { Total no. of stunted } / \text { underweight }}\right) \times 100
$$

or late term GA (i.e., 41 or 42 weeks) because the WHOGS are based on a reference population of children born between 37 and 42 weeks GA and are therefore intended to be applied directly to all children born in the 5-weeks span of 'term' gestation. However, as a sensitivity analysis we used CA for all children (including term-born children) in the application of WHO-GS at postnatal followup visits.

In additional sensitivity analyses, LAZ and WAZ for preterm-born children at the 3-month visit (i.e. within 64 weeks postmenstrual age) were derived using the INTERGROWTH-21st postnatal standards for pretermborn children based on the Preterm Postnatal Followup Study (IG-PPFS) [31]. The WHO-GS Anthro macro (www.who.int/childgrowth/software/en/) [32] and the INTERGROWTH-21st Newborn Size Application Tool (https://intergrowth21.tghn.org/global-perinatal-package/intergrowth-21st-comparison-application/) were used for the application of the reference/standard at birth.

\section{Statistical analysis}

Stillbirths $(n=56)$, twins $(n=80)$, or newborns with missing or implausible GA $(n=42)$ or missing both weight and length at birth $(n=2)$ were excluded from this study (see Additional file 1: Figure S1). In addition, anthropometric measurements taken outside \pm 1 month of the 3-month visit $(n=16)$, outside \pm 2 months of the 12 - and 24-month visits $(n=20)$, and outside \pm 6 months of the 48-month visit $(n=85)$ were excluded. Infants born at $<24^{0 / 7}$ weeks GA $(n=2)$ were excluded from analyses at birth as they were below the range of application of the IG-VPBR.

Repeated cross-sectional analyses were conducted to estimate and compare mean LAZ and WAZ derived
To further determine the effect of using CA versus postnatal age in the application of growth standards in a public health context, we simulated a population-based cross-sectional sample by randomly selecting each child at only one follow-up visit between birth and 48-months. All analyses were conducted using STATA, versions 13 and 14 Statistical Software package (StataCorp, LP).

\section{Results}

Of 4287 births in the cohort, data from 4107 children were eligible for inclusion in this study. Children born preterm $(n=482 ; 11.7 \%)$ had a mean \pm SD GA of $34.4 \pm 2.5$ weeks (median (interquartile range): 35 (2.0) weeks). Of the 482 children born preterm, $19.2 \%(n=92)$ were born at $\leq 33^{6 / 7}$ weeks and $81.3 \%(n=391)$ were born between $34^{0 / 7}$ and $36^{6 / 7}$ weeks GA. Mean \pm SD GA at birth among term-born children was $39.2 \pm 1.5$ weeks.

As expected, children born preterm were on average shorter and lighter than term-born children at birth and at each subsequent follow-up visit up to 48-months when anthropometric indices were assessed using WHO-GS with postnatal age. However, the magnitude of the mean differences in LAZ and WAZ among term- versus preterm-born children estimated using postnatal age attenuated with increasing age (Tables 1,2 ).

Using IG-VPBR and IG-NS at birth (i.e., CA vs postnatal age) shifted the distributions of LAZ and WAZ higher and resulted in significantly higher mean $z$ scores compared to WHO-GS. The effect was greatest among children born preterm as expected, but was also evident among term newborns (see Additional file 1: Figure S2; Tables 1, 2). Compared to estimates derived using WHOGS at birth, distributions of LAZ and WAZ based on IGVPBR and IG-NS had lower variance, shorter left-tails, 


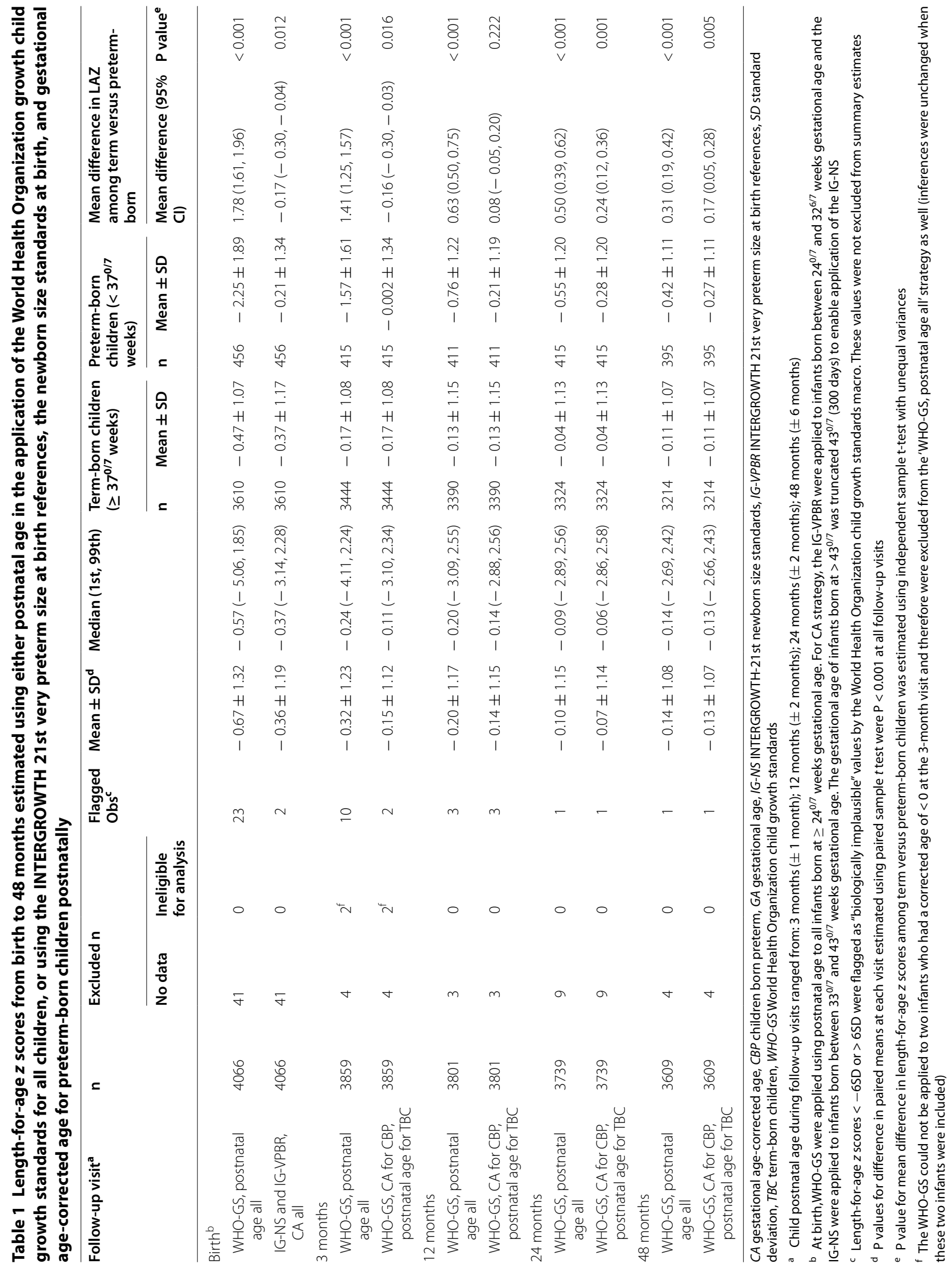




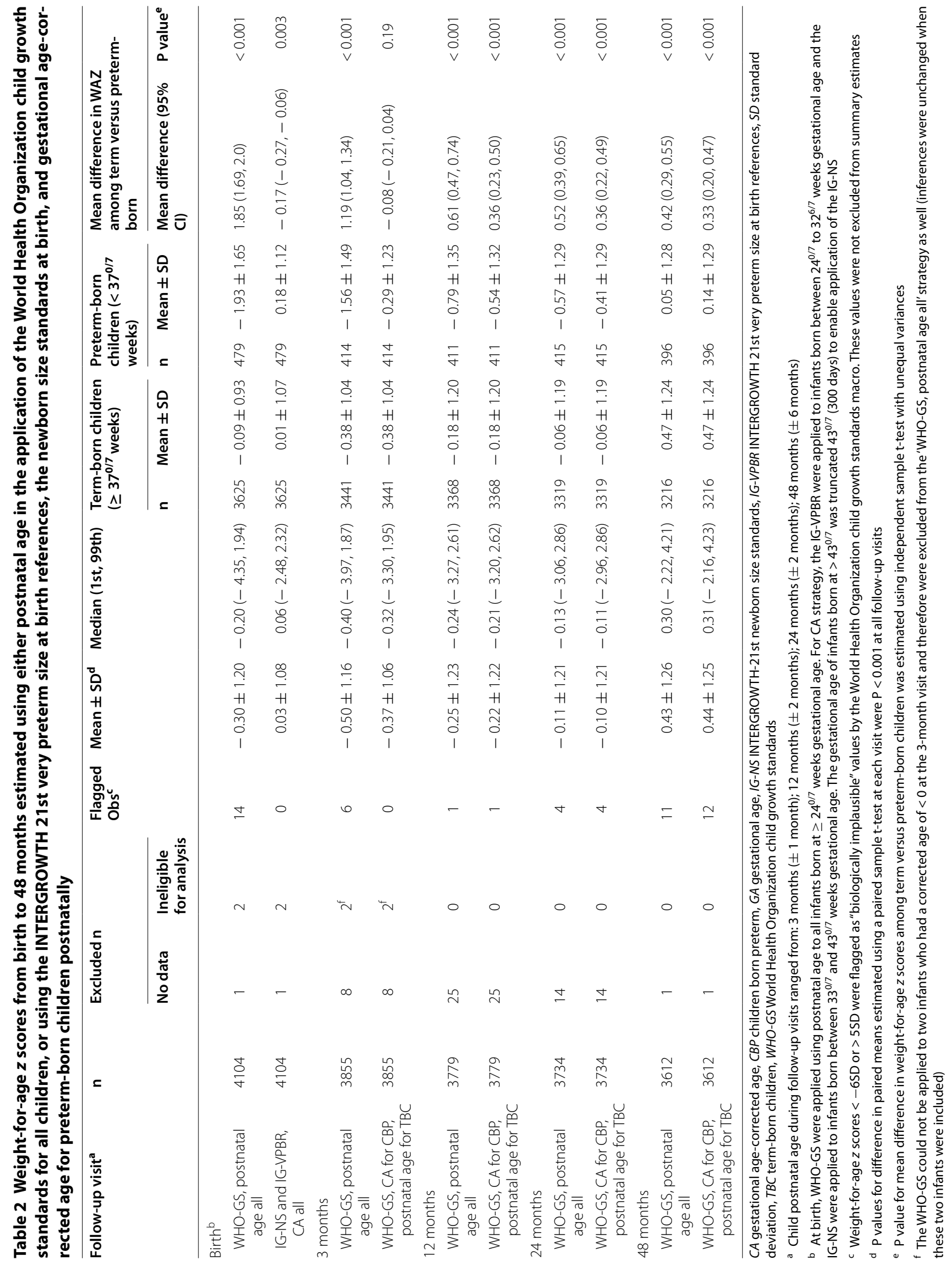


and were more normal appearing (i.e., skewness and kurtosis values were closer to a normal distribution; data not shown). At follow-up visits, children born preterm continued to have higher mean LAZ and WAZ using CA compared to postnatal age; however, the magnitude of the effect attenuated over time (Tables 1,2) and the distributions of LAZ and WAZ based on CA versus postnatal age were essentially overlapping by the 12 month visit (see Additional file 1: Figure S2).

At birth, using CA (vs postnatal age) attenuated the overall prevalence of stunting $(8.3$ vs $11.6 \%)$ and underweight (3.7 vs $6.9 \%$ ) (Tables 3,4 ). Similarly, at the 3-month visit, using CA versus postnatal age reduced the overall prevalence of stunting (5.1 vs 7.8\%) and underweight (6.6 vs 9.3\%). Although estimates varied slightly, inferences remained unchanged when $\mathrm{CA}$ was used for all children (including term-born children) at postnatal follow-up visits (see Additional file 1: Tables S1 and S2) or when IG-PPFS with postmenstrual age were used for preterm-born children at the 3-month visit (see Additional file 1: Tables S3 and S4). The effect of using CA for children born preterm was attenuated by the 12 month visit.

Table 3 Prevalence, odds of stunting (length-for-age $z$ score < - 2) among children born preterm compared to term-born children, and the population attributable risk of stunting due to preterm birth, estimated using postnatal or gestational age-corrected age from birth to the 48-month follow-up visit

\begin{tabular}{|c|c|c|c|c|c|c|c|c|c|}
\hline \multirow[t]{2}{*}{ Follow-up visit ${ }^{a}$} & \multirow[t]{2}{*}{$\mathbf{N}$} & \multicolumn{2}{|c|}{ Overall stunted } & \multicolumn{2}{|c|}{$\begin{array}{l}\text { Term-born } \\
\text { children } \\
\left(\geq 37^{0 / 7} \text { weeks) }\right.\end{array}$} & \multicolumn{2}{|c|}{$\begin{array}{l}\text { Preterm-born } \\
\text { children } \\
\left(<37^{0 / 7} \text { weeks }\right)\end{array}$} & \multirow{2}{*}{$\begin{array}{l}\text { Odds of stunting } \\
\text { among preterm ver- } \\
\text { sus term-born children } \\
\text { OR }(95 \% \mathrm{Cl})\end{array}$} & \multirow[t]{2}{*}{$\begin{array}{l}\% \text { Population attrib- } \\
\text { utable risk }^{\mathbf{d}}\end{array}$} \\
\hline & & n (\%) & $\mathrm{P}^{\mathrm{c}}$ & $\mathbf{n}$ & $\begin{array}{l}\text { Stunted } \\
\mathrm{n}(\%)\end{array}$ & $\mathbf{n}$ & $\begin{array}{l}\text { Stunted } \\
\mathrm{n}(\%)\end{array}$ & & \\
\hline \multicolumn{10}{|l|}{ Birth $^{b}$} \\
\hline $\begin{array}{l}\text { WHO-GS, postnatal age } \\
\quad \text { all }\end{array}$ & 4066 & $473(11.6)$ & $<0.001$ & 3610 & $240(6.65)$ & 456 & $233(51.1)$ & $14.7(11.7,18.4)$ & 42.9 \\
\hline IG-NS and IG-VPBR, CA all & 4066 & $337(8.29)$ & & 3610 & $290(8.03)$ & 456 & $47(10.3)$ & $1.32(0.95,1.82)$ & 3.08 \\
\hline \multicolumn{10}{|l|}{3 months } \\
\hline $\begin{array}{l}\text { WHO-GS, postnatal age } \\
\quad \text { all }\end{array}$ & $3859^{e}$ & $299(7.75)$ & $<0.001$ & 3444 & $166(4.82)$ & 415 & $133(32.0)$ & $9.31(7.19,12.1)$ & 37.8 \\
\hline $\begin{array}{l}\text { WHO-GS, CA for CBP, } \\
\text { postnatal age for TBC }\end{array}$ & $3859^{e}$ & $195(5.05)$ & & 3444 & $166(4.82)$ & 415 & $29(6.99)$ & $1.48(0.99,2.23)$ & 4.61 \\
\hline \multicolumn{10}{|l|}{12 months } \\
\hline $\begin{array}{l}\text { WHO-GS, postnatal age } \\
\quad \text { all }\end{array}$ & 3801 & $221(5.81)$ & $<0.001$ & 3390 & $160(4.7)$ & 411 & $61(14.8)$ & $3.52(2.57,4.82)$ & 18.8 \\
\hline $\begin{array}{l}\text { WHO-GS, CA for CBP, } \\
\text { postnatal age for TBC }\end{array}$ & 3801 & $191(5.02)$ & & 3390 & $160(4.7)$ & 411 & $31(7.54)$ & $1.65(1.11,2.45)$ & 6.07 \\
\hline \multicolumn{10}{|l|}{24 months } \\
\hline $\begin{array}{l}\text { WHO-GS, postnatal age } \\
\quad \text { all }\end{array}$ & 3739 & $181(4.84)$ & 0.002 & 3324 & $132(4.0)$ & 415 & $49(11.8)$ & $3.24(2.29,4.57)$ & 18.0 \\
\hline $\begin{array}{l}\text { WHO-GS, CA for CBP, } \\
\text { postnatal age for TBC }\end{array}$ & 3739 & $168(4.49)$ & & 3324 & $132(4.0)$ & 415 & $36(8.67)$ & $2.30(1.57,3.37)$ & 11.6 \\
\hline \multicolumn{10}{|l|}{48 months } \\
\hline $\begin{array}{l}\text { WHO-GS, postnatal age } \\
\quad \text { all }\end{array}$ & 3609 & $128(3.55)$ & 0.03 & 3214 & $98(3.1)$ & 395 & $30(7.60)$ & $2.61(1.71,3.99)$ & 14.0 \\
\hline $\begin{array}{l}\text { WHO-GS, CA for CBP, } \\
\text { postnatal age for TBC }\end{array}$ & 3609 & $122(3.38)$ & & 3214 & $98(3.1)$ & 395 & $24(6.08)$ & $2.06(1.30,3.26)$ & 9.80 \\
\hline \multicolumn{10}{|c|}{$\begin{array}{l}\text { CA gestational age-corrected age, CBP children born preterm, } C \text { confidence interval, GA gestational age, IG-NS INTERGROWTH } 21 \text { st newborn size standards, IG-VPBR } \\
\text { INTERGROWTH } 21 \text { st very preterm size at birth references, OR odds ratio, PAR population attributable risk, TBC term-born children, WHO-GS World Health Organization } \\
\text { child growth standards }\end{array}$} \\
\hline \multirow{2}{*}{\multicolumn{10}{|c|}{$\begin{array}{l}\text { a Child postnatal age during follow-up visits ranged from: } 3 \text { months ( } \pm 1 \text { month); } 12 \text { months ( } \pm 2 \text { months); } 24 \text { months ( } \pm 2 \text { months); } 48 \text { months ( } \pm 6 \text { months) } \\
\text { b At birth, the WHO-GS were applied using postnatal age to all infants born at } \geq 24^{0 / 7} \text { weeks gestational age. For CA strategy, the IG-VPBR were applied to infants } \\
\text { born between } 24^{0 / 7} \text { and } 32^{6 / 7} \text { weeks gestational age and the IG-NS were applied to infants born between } 33^{0 / 7} \text { and } 43^{0 / 7} \text { weeks gestational age. The gestational age of } \\
\text { infants born at }>43^{0 / 7} \text { was truncated } 43^{0 / 7} \text { ( } 300 \text { days) to enable application of the IG-NS }\end{array}$}} \\
\hline & & & & & & & & & \\
\hline \multicolumn{10}{|c|}{$\begin{array}{l}\text { 'P values from McNemar's test for difference in paired proportions when using GA-c } \\
\text { d Proportion of all stunting in the population that is attributable to preterm }\end{array}$} \\
\hline${ }^{d}$ Proportion of all stunting in & the popul & lation that is a & attributable & to prete & $\mathrm{rm}$ & & & & \\
\hline
\end{tabular}


Table 4 Prevalence, odds of underweight (weight-for-age $z$ score < - 2) among children born preterm compared to termborn children, and the population attributable risk of underweight due to preterm birth, estimated using postnatal or gestational age-corrected age from birth to the 48-month follow-up visit

\begin{tabular}{|c|c|c|c|c|c|c|c|c|c|}
\hline \multirow[t]{2}{*}{ Follow-up visit ${ }^{a}$} & \multirow[t]{2}{*}{$\mathrm{N}$} & \multicolumn{2}{|c|}{$\begin{array}{l}\text { Overall under- } \\
\text { weight }\end{array}$} & \multicolumn{2}{|c|}{$\begin{array}{l}\text { Term-born children } \\
\text { ( } \geq 37^{0 / 7} \text { weeks) }\end{array}$} & \multicolumn{2}{|c|}{$\begin{array}{l}\text { Preterm-born } \\
\text { children }\left(<37^{0 / 7}\right. \\
\text { weeks })\end{array}$} & \multirow{2}{*}{$\begin{array}{l}\text { Odds of underweight } \\
\text { among preterm } \\
\text { versus term-born } \\
\text { children } \\
\text { OR }(95 \% \mathrm{Cl})\end{array}$} & \multirow[t]{2}{*}{$\begin{array}{l}\% \text { Population attrib- } \\
\text { utable risk }^{\mathrm{d}}\end{array}$} \\
\hline & & n (\%) & $P^{c}$ & $\mathbf{n}$ & $\begin{array}{l}\text { Underweight } \\
\text { n (\%) }\end{array}$ & $\mathrm{n}$ & $\begin{array}{l}\text { Underweight } \\
\text { n (\%) }\end{array}$ & & \\
\hline \multicolumn{10}{|l|}{ Birth $^{b}$} \\
\hline $\begin{array}{l}\text { WHO-GS, postnatal } \\
\text { age all }\end{array}$ & 4104 & $284(6.92)$ & $<0.001$ & 3625 & $101(2.79)$ & 479 & $183(38.2)$ & $21.6(16.5,28.3)$ & 59.7 \\
\hline $\begin{array}{l}\text { IG-NS and IG-VPBR, } \\
\text { CA all }\end{array}$ & 4104 & $151(3.68)$ & & 3625 & $129(3.56)$ & 479 & $22(4.59)$ & $1.30(0.82,2.07)$ & 3.28 \\
\hline \multicolumn{10}{|l|}{3 months } \\
\hline $\begin{array}{l}\text { WHO-GS, postnatal } \\
\text { age all }\end{array}$ & $3855^{e}$ & $359(9.31)$ & $<0.001$ & 3441 & $220(6.39)$ & 414 & $139(33.6)$ & $7.40(5.79,9.46)$ & 31.3 \\
\hline $\begin{array}{l}\text { WHO-GS, CA for CBP, } \\
\text { postnatal age for } \\
\text { TBC }\end{array}$ & $3855^{e}$ & $254(6.59)$ & & 3441 & $220(6.39)$ & 414 & $34(8.21)$ & $1.31(0.90,1.91)$ & 2.97 \\
\hline \multicolumn{10}{|l|}{12 months } \\
\hline $\begin{array}{l}\text { WHO-GS, postnatal } \\
\text { age all }\end{array}$ & 3779 & $282(7.46)$ & $<0.001$ & 3368 & $214(6.35)$ & 411 & $68(16.5)$ & $2.92(2.18,3.92)$ & 14.9 \\
\hline $\begin{array}{l}\text { WHO-GS, CA for CBP, } \\
\text { postnatal age for } \\
\text { TBC }\end{array}$ & 3779 & $262(6.93)$ & & 3368 & $214(6.35)$ & 411 & $48(11.7)$ & $1.95(1.40,2.71)$ & 8.35 \\
\hline \multicolumn{10}{|l|}{24 months } \\
\hline $\begin{array}{l}\text { WHO-GS, postnatal } \\
\text { age all }\end{array}$ & 3734 & 199 (5.33) & 0.03 & 3319 & $157(4.73)$ & 415 & $42(10.1)$ & $2.27(1.59,3.24)$ & 11.2 \\
\hline $\begin{array}{l}\text { WHO-GS, CA for CBP, } \\
\text { postnatal age for } \\
\text { TBC }\end{array}$ & 3734 & $193(5.17)$ & & 3319 & $157(4.73)$ & 415 & $36(8.67)$ & $1.91(1.31,2.79)$ & 8.48 \\
\hline \multicolumn{10}{|l|}{48 months } \\
\hline $\begin{array}{l}\text { WHO-GS, postnatal } \\
\text { age all }\end{array}$ & 3612 & $56(1.55)$ & 0.24 & 3216 & $40(1.24)$ & 396 & $16(4.04)$ & $3.34(1.85,6.03)$ & 19.8 \\
\hline $\begin{array}{l}\text { WHO-GS, CA for CBP, } \\
\text { postnatal age for } \\
\text { TBC }\end{array}$ & 3612 & $53(1.47)$ & & 3216 & $40(1.24)$ & 396 & $13(3.28)$ & $2.70(1.43,5.08)$ & 15.2 \\
\hline
\end{tabular}

CA gestational age-corrected age, CBP children born preterm, Cl confidence interval, GA gestational age, IG-NS INTERGROWTH 21st newborn size standards, IG-VPBR INTERGROWTH 21st very preterm size at birth references, OR odds ratio, $P A R$ population attributable risk, TBC term-born children, WHO-GS World Health Organization child growth standards

${ }^{\text {a }}$ Child postnatal age during follow-up visits ranged from: 3 months ( \pm 1 month); 12 months ( \pm 2 months); 24 months ( \pm 2 months); 48 months ( \pm 6 months)

${ }^{b}$ At birth, the WHO-GS were applied using postnatal age to all infants born at $\geq 24^{0 / 7}$ weeks gestational age. For CA strategy, the IG-VPBR were applied to infants born between $24^{0 / 7}$ and $32^{6 / 7}$ weeks gestational age and the IG-NS were applied to infants born between $33^{0 / 7}$ and $43^{0 / 7}$ weeks gestational age. The gestational age of infants born at $>43^{0 / 7}$ was truncated $43^{0 / 7}$ (300 days) to enable application of the IG-NS

c P values from McNemar's test for difference in paired proportions when using GA-corrected strategy versus 'WHO-GS, postnatal age all' (reference)

${ }^{d}$ Proportion of all stunting in the population that is attributable to preterm births

e The WHO-GS could not be applied to two infants who had a corrected age of $<0$ at the 3-month visit and therefore were excluded from the 'WHO-GS, postnatal age all'strategy as well (inferences were unchanged when these two infants were included)

Compared to term-born infants, children born preterm had higher estimated mean LAZ/WAZ and attenuated odds of stunting/underweight at birth and 3 months when using $\mathrm{CA}$, which was opposite to the inferences based on postnatal age. From 12 to 48 months, children born preterm were at higher risks of stunting and underweight relative to term-born children when using both
CA and postnatal age; however, ORs and \%PARs were consistently overestimated using postnatal age (Tables 3 , 4). The apparent patterns of change in ORs/\%PARs with age were substantially influenced by the choice of age scale: using postnatal age, the odds ratio for stunting and underweight among preterm-born versus term-born children decreased from birth up to at least the 24-month 
visit, whereas using CA the odds ratios increased from birth up to at least the 24-month visit (Fig. 2). Similarly, using postnatal age, the \%PAR of stunting and underweight due to preterm birth decreased from birth up to the 48-month visit, but an opposite (increasing) trend was observed when CA was used to estimate the \%PAR

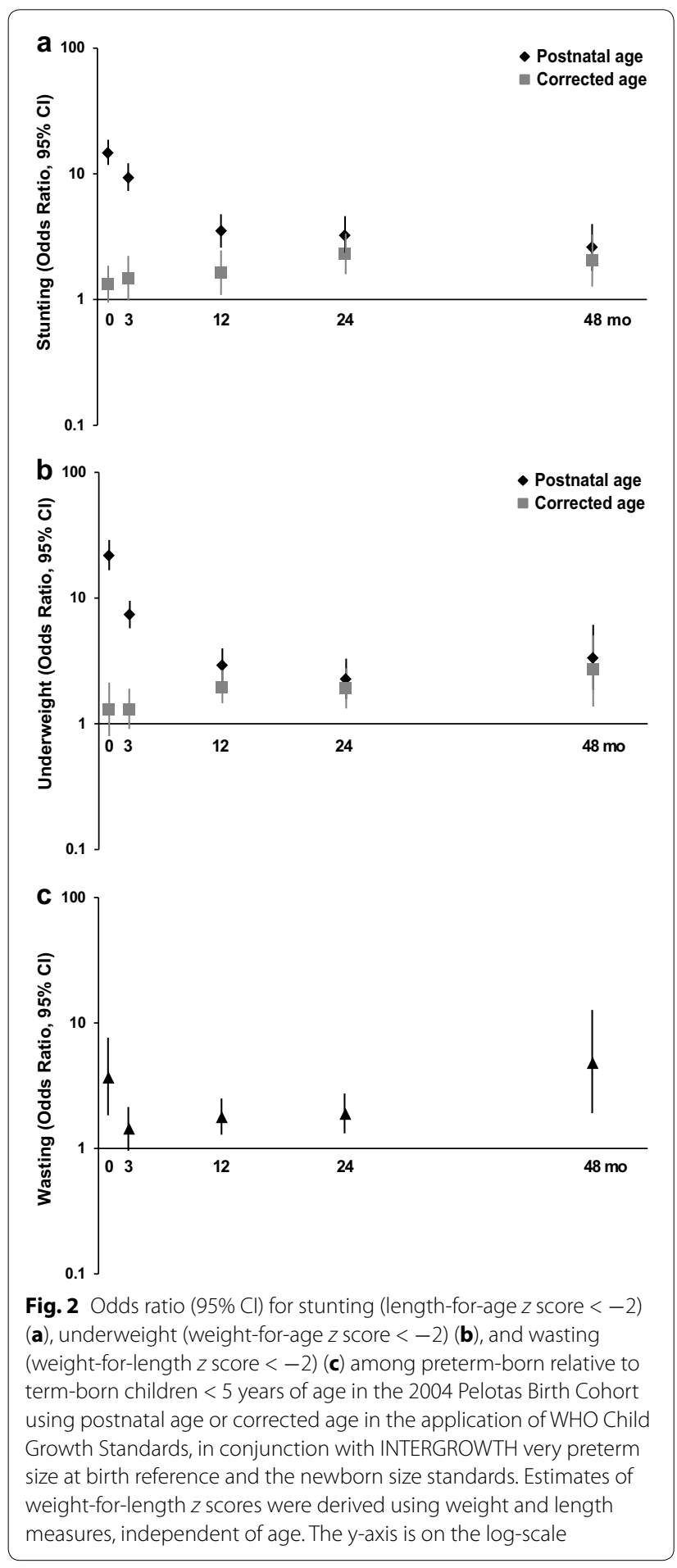

due to preterm birth (Tables 3, 4). Of note, the magnitude of the estimates and the trends over time for stunting and underweight among children born preterm derived using CA were more closely aligned with trends in wasting, a measure of undernutrition that is estimated independently of age (Fig. 2; see Additional file 1: Table S5).

In a cross-sectional random sample of children from birth to 48 months of age, using GA-specific norms at birth alone and WHO-GS using postnatal age for all children after birth substantially attenuated the mean LAZ/ WAZ and the prevalence of undernutrition at the population-level compared to using WHO-GS at birth and postnatal visits. In comparison, using CA for pretermborn children instead of postnatal age for all children when applying the WHO-GS postnatally did not greatly influence the overall estimates of the mean LAZ/WAZ or prevalence of undernutrition; however, use of postnatal age overestimated the relative odds of stunting and underweight in preterm-born versus term-born children considerably (Table 5).

\section{Discussion}

Using postnatal age in the application of growth standards for all children in a birth cohort in Brazil overestimated the population-average estimates of undernutrition and inflated the associations between preterm birth and undernutrition. Incorporating information about gestational duration by using $\mathrm{CA}$ altered indices and indicators of child nutritional status at the population-level and changed inferences with respect to the relative odds of undernutrition among children born preterm in the newborn and early infancy period. The odds of stunting and underweight due to preterm birth were diminished using CA versus postnatal age at birth; however, as expected, the effect of using CA compared to postnatal age on population-average estimates of child nutritional status progressively attenuated overtime. Beyond the 12-month follow-up, the effect of using CA on population-average cross-sectional estimates appeared to be minimal. Although the inferences at the 12- and 24-month follow-up in this study are consistent with previously reported findings from this cohort [15], the magnitude of the associations between preterm birth and stunting and underweight were attenuated when CA compared to postnatal age was used. Importantly, in contrast to estimates derived using postnatal age, we observed an increasing postnatal association between preterm birth and stunting and underweight during the first 2 years of life when CA was used. This suggests that preterm-born children in this cohort were not more likely than term infants to be undernourished at birth, but had a higher likelihood of becoming stunted and underweight beyond the early postnatal period. 


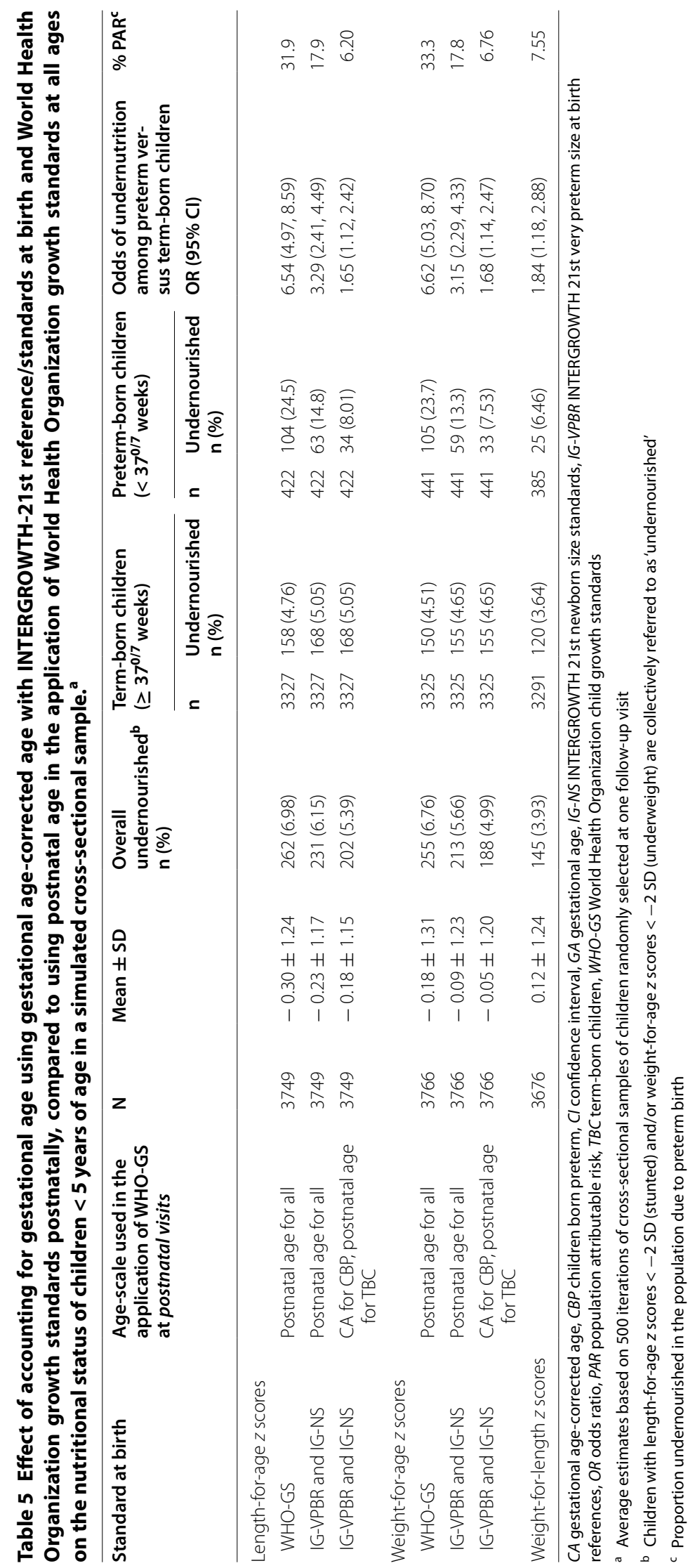


As expected, using postnatal age for children born preterm in the application of WHO-GS leads to systematic bias in the measurement of nutritional status during infancy as anthropometric measures are standardized based on expected size for a given age from birth (i.e. postnatal age) as opposed to age from conception (estimated by the postmenstrual age scale). The extent to which anthropometric $z$ scores are misclassified-and therefore the effect of misclassification on measures of association where child nutritional status is either the exposure or outcome-depends on the incidence of preterm birth in the source population as well as the distribution of GA among children born preterm. In LMICs where a large proportion of children are born preterm-estimated to range from 10 to $18 \%$ [34]the misclassification of infant nutritional status is nonnegligible. Given the importance of gestational duration in early infancy, the effect of using CA on relative measures of associations is apparent even in the context of a cross-sectional survey in which anthropometric data are pooled from a sample of infants and young children at various ages. These findings demonstrate that population-based epidemiologic studies in LMICs [12-15] may overestimate the prevalence of undernutrition and the risk of undernutrition among preterm-born relative to term-born children, if GA is unavailable or unused in the application of growth standards.

Although the importance of using CA in analyses of anthropometric data is most apparent in early infancy (i.e., birth and 3 months), there are no known disadvantages of using CA up to 24 months of age in epidemiologic analyses, as is commonly done in clinical practice. In fact, using a GA-specific age scale in the application of growth standards confers several analytical advantages, including: (1) lower frequency of "biologically-implausible" outliers (i.e. LAZ $<-6$ or $>6$ SD; WAZ $<-6$ or $>5$ $\mathrm{SD})$ [32], which may in part be due to incorrect assignment of $z$ scores to preterm-born children, (2) reduced variance in the distribution of $z$ scores leading to greater precision in the standard errors, and (3) improved normality of the $z$ score distributions during early infancy.

An important limitation of this study was the use of a derived GA variable based on LMP and Dubowitz methods. These methods for GA assessment are less precise in comparison to first or second trimester ultrasound assessment. To minimize the risk of measurement error, we excluded all observations with implausible birthweight and GA combinations, which may have resulted in some selection bias by excluding observations at extreme ends of the birthweight-for-GA distribution. However, given that available ultrasound measurements in this cohort were prone to selection bias for preterm births, the systematically derived GA estimate provided a more reliable measure of GA for this study. Importantly, inferences regarding the effect of using CA compared to postnatal age for preterm-born children in the application of growth standards are robust against GA estimation methods. The effect of using CA for children born preterm in the application of WHO-GS in this study was likely a conservative estimate given the lower prevalence of undernutrition in Pelotas, Brazil, compared to countries in Sub-Saharan Africa and South Asia [10]. In addition, due to the repeated serial cross-sectional design of our analysis, we did not analyze individual-level longitudinal patterns of growth among preterm-born children using different age-scales in the application of growth standards. Furthermore, although we used the best available standards at each follow-up visit (e.g., IG-NS, IGPPFS, and WHO-GS), it was difficult to fully disentangle the implications of using different standards (INTERGROWTH-21st vs WHO-GS) from GA-correction effect alone for comparisons at birth. However, the effects of using CA for preterm-born children (or using CA for all children in sensitivity analyses) at the 3-month and later visits were assessed using only WHO-GS, and therefore demonstrated that observed differences in $\mathrm{CA}$ versus postnatal age estimates were not an artifact of differences in standards but a true effect of accounting for GA in the standardization of anthropometric indices and indicators. Nonetheless, further research is needed to fully explore the implications of combining multiple different standards for longitudinal assessment of child growth trajectories.

In summary, this study suggests that the choice of age scale used to standardize anthropometric measures has substantial and meaningful implications for population-level epidemiologic inferences related to patterns of growth faltering and risk factors that contribute to undernutrition in early life. In LMICs with concurrently high prevalence of undernutrition and high incidence of preterm births, the discrepancies between postnatal age versus $\mathrm{CA}$ estimates of undernutrition at the population-level would be expected to be greater than the effect observed in this study, and may potentially misguide public health intervention priorities to reduce the population burden of undernutrition Future epidemiologic studies should therefore collect high-quality information about GA whenever possible and incorporate the GA information in the analyses of anthropometric data, at least at birth and during infancy. Longitudinal studies that account for heterogeneity in GA at birth in the application of growth standards are needed to better understand postnatal growth trajectories among children born preterm, the contribution of preterm birth to undernutrition in early life, and the implications for health outcomes in later life. 


\section{Additional file}

Additional file 1. Supplementary figures and tables.

\begin{abstract}
Abbreviations
CA: gestational-age corrected age; GA: gestational age; INTERGROWTH-21 st: International Fetal and Newborn Growth Consortium for the 21st century; IGNS: INTERGROWTH-21st newborn size standards; IG-PPFS: INTERGROWTH-21st postnatal standards for preterm born children; IG-VPBR: INTERGROWTH-21st very preterm size at birth references; LAZ: length-for-age z scores; LMP: last menstrual period; WAZ: weight-for-age z scores; PAR: population attributable risk; WFLZ: weight-for-length z score; WHO-GS: World Health Organization Growth Standards.
\end{abstract}

\section{Authors' contributions}

NP, DER, and DGB designed the research; AJDB, ISS, and AM conducted the 2004 Pelotas Birth cohort study and provided essential materials; NP, DER, JP, and DGB conducted the research; NP analyzed the data and wrote the first draft of the paper; NP, DER, and DGB iteratively revised the paper; NP had primary responsibility for the final content. All authors read and approve the final manuscript.

\begin{abstract}
Author details
1 Department of Epidemiology, Dalla Lana School of Public Health, University of Toronto, Toronto, ON, Canada. ${ }^{2}$ Centre for Global Child Health, Child Health Evaluative Sciences, Hospital for Sick Children, 686 Bay Street, Toronto, ON M5G 0A4, Canada. ${ }^{3}$ Division of Paediatric Medicine, Hospital for Sick Children, Toronto, ON, Canada. ${ }^{4}$ Departments of Paediatrics and Nutritional Sciences, University of Toronto, Toronto, ON, Canada. ${ }^{5}$ Postgraduate Program in Epidemiology, Federal University of Pelotas, Pelotas, Rio Grande do Sul, Brazil. ${ }^{6}$ Department of Preventive Medicine, School of Medicine, University of São Paulo, São Paulo, Brazil.
\end{abstract}

\section{Acknowledgements}

The authors would like to acknowledge Romina Buffarini for her assistance in translating the variable codebooks for the Pelotas Birth Cohort Studies.

\section{Competing interests}

The authors declare that they have no competing interests.

\section{Availability of data and materials}

The data that support the findings of this study are available from the 2004 Pelotas (Brazil) Cohort Study Investigators but restrictions apply to the availability of these data, which were used under license for the current study, and so are not publicly available. Data are however available from the 2004 Pelotas Cohort Study upon completion of the data request application form that can be obtained by contacting the 2004 Pelotas Cohort Study Investigators.

\section{Ethics approval and consent to participate}

The cohort study was approved by the Research Ethics Committee of the Medical School of the Universidade Federal de Pelotas for all follow-ups and, in addition, the World Health Organization Ethics Committee (Geneva) for data collected at birth. Ethical approval for this analysis was obtained from the Hospital for Sick Children, Toronto, Canada (REB \#100053026) and the University of Toronto (Protocol Reference \#34198).

\section{Funding}

No funding was involved in the conduct of this study. This research was supported in part by the Canadian Institutes for Health Research Doctoral Research Award training grant to NP. The Pelotas Birth Cohort, 2004 study is conducted by the Postgraduate Program in Epidemiology at Universidade Federal de Pelotas, with the collaboration of the Brazilian Public Health Association (ABRASCO). From 2009 to 2013, the Wellcome Trust supported the 2004 birth cohort study. The World Health Organization, National Support Program for Centers of Excellence (PRONEX), Brazilian National Research Council (CNPq), Brazilian Ministry of Health, and Children's Pastorate supported previous phases of the study. The sponsors had no role in the design of the study, the collection, analysis, and interpretation of data, or in the writing of the manuscript.

\section{Publisher's Note}

Springer Nature remains neutral with regard to jurisdictional claims in published maps and institutional affiliations.

Received: 19 April 2017 Accepted: 24 January 2018

Published online: 06 February 2018

\section{References}

1. Black RE, Allen LH, Bhutta ZA, Caulfield EL, De Onis M, Ezzati M, et al. Maternal and child undernutrition: global and regional exposures and health consequences. Lancet. 2008;371:243-60.

2. Grantham-McGregor S, Cheung YB, Cueto S, Glewwe P, Richter L, Strupp B. Developmental potential in the first 5 years for children in developing countries. Lancet. 2007;369:60-70.

3. Chen LC, Chowdhury A, Huffman SL. Anthropometric assessment of energy-protein malnutrition and subsequent risk of mortality among preschool aged children. Am J Clin Nutr. 1980;33:1836-45.

4. Walker SP, Chang SM, Powell CA. The association between early childhood stunting and weight status in late adolescence. Int J Obes. 2007;31:347-52.

5. Alderman $\mathrm{H}$, Hoogeveen $\mathrm{H}$, Rossi M. Preschool nutrition and subsequent schooling attainment: longitudinal evidence from Tanzania. Econ Dev Cult Change. 2009;57:239-60.

6. Horton S, Heckel RH. Malnutrition: global economic losses attributable to malnutrition 1900-2000 and projections to 2050. In: Lomborg B, editor. How much have global problems cost the earth? A scorecard from 1900 to 2050. New York: Cambridge University Press; 2013. p. 247-72.

7. Adair LS, Fall CHD, Osmond C, Stein AD, Martorell R, Ramirez-Zea M, et al. Associations of linear growth and relative weight gain during early life with adult health and human capital in countries of low and middle income: findings from five birth cohort studies. Lancet. 2013;382:525-34.

8. Barker DJP. Growth in utero, blood pressure in childhood and adult life, and mortality from cardiovascular disease. BMJ. 1989;298:564-7.

9. Stein AD, Barros FC, Bhargava SK, Hao W, Horta BL, Lee N, et al. Birth status, child growth, and adult outcomes in low- and middle-income countries. J Pediatr. 2013;163:1740-6.

10. Stevens GA, Finucane MM, Paciorek CJ, Flaxman SR, White RA, Donner AJ, et al. Trends in mild, moderate, and severe stunting and underweight, and progress towards MDG 1 in 141 developing countries: a systematic analysis of population representative data. Lancet. 2012;380:824-34.

11. Black RE, Victora CG, Walker SP. Maternal and child undernutrition and overweight in low-income and middle-income countries. Lancet. 2013;382:427-51.

12. Christian $P$, Lee $S E$, Angel MD, Adair LS, Arifeen SE, Ashorn P, et al. Risk of childhood undernutrition related to small-for-gestational age and preterm birth in low- and middle-income countries. Int J Epidemiol. 2013:42:1340-55

13. Danaei G, Andrews KG, Sudfeld CR, Fink G, McCoy DC, Peet E, et al. Risk factors for childhood stunting in 137 developing countries: a comparative risk assessment analysis at global, regional, and country levels. PLoS Med. 2016;13:e1002164.

14. Sania A, Spiegelman D, Rich-Edwards J, Okuma J, Kisenge R, Msamanga $\mathrm{G}$, et al. The contribution of preterm birth and intrauterine growth restriction to infant mortality in Tanzania. Paediatr Perinat Epidemiol. 2014;28:23-31.

15. Santos IS, Matijasevich A, Domingues MR, Barros AJ, Victora CG, Barros FC Late preterm birth is a risk factor for growth faltering in early childhood: a cohort study. BMC Pediatr. 2009;9:71.

16. de Onis M, Onyango A, Borghi E, Siyam A, Blossner M, Lutter C, et al. Worldwide implementation of the WHO child growth standards. Public Health Nutr. 2012;15:1603-10.

17. de Onis M, Garza C, Victora CG, Onyango AW, Frongillo EA, Martines JC, et al. The WHO Multicentre Growth Reference Study: planning, study design, and methodology. Food Nutr Bull. 2004;25:S15-26. 
18. Villar J, Knight HE, De Onis M, Bertino E, Gilli G, Papageorghiou AT, et al. Conceptual issues related to the construction of prescriptive standards for the evaluation of postnatal growth of preterm infants. Arch Dis Child. 2010;95:1034-8.

19. Dietitions of Canada, Canadian Paediatric Society. Promoting optimal monitoring of child growth in Canada: using the new WHO growth charts. Collaborative public policy statement. 2010. http://www.dietitians. ca/Downloads/Public/tcg-position-paper.aspx. Accessed 11 July 2016

20. Engle WA. Age terminology during the perinatal period. Pediatrics. 2004;114:1362-4.

21. Villar J, Ismail LC, Victora CG, Ohuma EO, Bertino E, Altman DG, et al. International standards for newborn weight, length, and head circumference by gestational age and sex: the Newborn Cross-Sectional Study of the INTERGROWTH-21st Project. Lancet. 2014;384:857-68.

22. Villar J, Giuliani F, Fenton TR, Ohuma EO, Ismail LC, Kennedy SH, INTERGROWTH-21st very preterm size at birth reference charts. Lancet. 2016;387:844-5.

23. Joseph KS. The fetuses-at-risk approach: causal and noncusal models. In: Louis GB, Platt RW, editors. Reproductive and perinatal epidemiology. New York: Oxford University Press; 2011.

24. Wang Z, Sauve RS. Assessment of postneonatal growth in VLBW infants: selection of growth references and age adjustment for prematurity. Can J Public Health. 1998;8:109-14.

25. Sherry B, Mei Z, Grummer-Strawn L, Dietz WH. Evaluation of and recommendations for growth references for very low birth weight $(\leq 1500$ grams) infants in the United States. Pediatrics. 2003;111:750-8.

26. Perumal N, Gaffey MF, Bassani DG, Roth DE. WHO child growth standards are often incorrectly applied to children born preterm in epidemiologic research. J Nutr. 2015:145:2429-39.
27. Barros AJD, Santos IS, Victora CG, Albernaz EP, Domingues MR, Timm IK, et al. The 2004 Pelotas birth cohort: methods and description. Rev Saude Publica. 2006;40:402-13.

28. Santos IS, Barros AJD, Matijasevich A, Zanini R, Cesar MAC, CamargoFiguera FA, et al. Cohort profile update: 2004 Pelotas (Brazil) Birth Cohort Study. Body composition, mental health and genetic assessment at the 6 years follow-up. Int J Epidemiol. 2014:43:1437-1437f.

29. Committee on Obstetric Practice American Institute of Ultrasound in Medicine Society for Maternal-Fetal Medicine. Committee opinion on 611: method for estimating due date. Obstet Gynaecol. 2014;24(4):863-6.

30. Fenton TR, Kim JH. A systematic review and meta-analysis to revise the Fenton growth chart for preterm infants. BMC Pediatr. 2013;13:59.

31. Villar J, Giuliani F, Bhutta ZA, Bertino E, Ohuma EO, Ismail LC, et al. Postnatal growth standards for preterm infants: the Preterm Postnatal Follow-up Study of the INTERGROWTH-21(st) Project. Lancet Glob Health. 2015;3:e681-91.

32. World Health Organization. Child growth standards software. WHO Anthro (version 3.2.2, January 2011) and macros. http://www.who.int/ childgrowth/software/en/.

33. Rothman KJ. Measuring disease occurence and causal effects. In: Epidemiology: an introduction. 2nd ed. Oxford University Press; 2012. pp. 65-7

34. Blencowe $H$, Cousens S, Oestergaard MZ, Chou D, Moller AB, Narwal R, et al. National, regional, and worldwide estimates of preterm birth rates in the year 2010 with time trends since 1990 for selected countries: a systematic analysis and implications. Lancet. 2012;379:2162-72.

\section{Submit your next manuscript to BioMed Central and we will help you at every step:}

- We accept pre-submission inquiries

- Our selector tool helps you to find the most relevant journal

- We provide round the clock customer support

- Convenient online submission

- Thorough peer review

- Inclusion in PubMed and all major indexing services

- Maximum visibility for your research

Submit your manuscript at www.biomedcentral.com/submit
O Biomed Central 